\title{
Factors Associated with Anemia among People Living with HIV/AIDS Taking ART in Ethiopia
}

\author{
Ketema Bizuwork Gebremedhin (D) and Tadesse Bedada Haye \\ School of Nursing and Midwifery, College of Health Sciences, Addis Ababa University, Addis Ababa, Ethiopia \\ Correspondence should be addressed to Ketema Bizuwork Gebremedhin; ketema.bizuwork@aau.edu.et
}

Received 30 August 2018; Revised 14 January 2019; Accepted 5 February 2019; Published 3 March 2019

Academic Editor: Aldo Roccaro

Copyright (C) 2019 Ketema Bizuwork Gebremedhin and Tadesse Bedada Haye. This is an open access article distributed under the Creative Commons Attribution License, which permits unrestricted use, distribution, and reproduction in any medium, provided the original work is properly cited.

\begin{abstract}
Background. Globally, anemia, among people living with HIV/AIDS, is a major public health problem. It has a significant effect on the progression of HIV/AIDS to advanced stages and there are a number of factors that often affect anemia. However, there is little insight regarding factors affecting anemia among HIV/AIDS patients in developing countries, including Ethiopia. Objective. This study aimed at investigating factors affecting anemia among people living with HIV/AIDS taking ART drug at Tikur Anbessa Specialized Hospital, Addis Ababa, Ethiopia. Methods. A hospital based cross-sectional study design was used to assess factors affecting anemia among people living with HIV/AIDS. Structured checklist was used to gather information from charts of patients selected by simple random sampling method. We analyzed the data to identify factors associated with anemia among people with HIV/AIDS using logistic regression models. Results. A total of 301 selected charts were reviewed. The median age was $38 \pm 10.38$. The majority (62.5\%) of the patients were taking ZDV-containing ART drug (ZDV/3TC/NVP). The overall anemia prevalence was $34.6 \%$, while about $5 \%, 15.6 \%$, and $14 \%$ of the patients had severe, moderate, and mild prevalence of anemia, respectively. Factors that were found to affect anemia among these patients include gender (OR $=2.26$ [95\% CI: 1.22, 4.16]), occupation (OR: 0.57 [95\%CI: $0.35,0.92])$, WBC count $(\mathrm{OR}=2.30$ [95\% CI: 1.29, 4.09]), platelet count (OR $=2.89$ [95\% CI: 0.99, 8.41]), nutritional status (OR $=2.05$ [95\% CI: 0.69, 6.02]), and WHO clinical stage of HIV/AIDS (OR = 3.69 [95\% CI: 1.86, 7.31]). Conclusions. About one in three patients was found to be anemic. Intervention aimed at diagnosing and treating anemia among people living with HIV/AIDS should be considered.
\end{abstract}

\section{Introduction}

Anemia is a major public health problem, especially in developing countries [1-3]. It has significant consequences on health and social and economic development of individuals [4]. The most common causes of anemia are deficiency of mineral, iron, and vitamin B12 [5], infestation of hookworm, malaria infection, vitamin A deficiency, genetic defects, and chronic infections like TB and HIV [6].

Undeniably, anemia is the most important clinical problem seen in people living with HIV/AIDS [7]; its severity increases as CD4 count declines [8] and with progression of the disease HIV/AIDS to advanced stage [9]. In addition, the higher anemia level by itself is also a good opportunity for progression of HIV/AIDS irrespective of CD4 counts level and viral load [10]. Moreover, anemia influences the natural history of the disease HIV/AIDS [11], resulting in the decrease of the survival rate. A number of previous studies from developing countries have demonstrated this evidence $[12,13]$.

HIV leads to declining the production of cytokine, which ultimately influences hematopoiesis process of the cells, specifically erythropoietin concentration [11]. This, in turn, results in ineffective/decreased production of red blood cells and/or increases their destruction [14]. The most common factors related to the reduced production of red blood cells are acquisition of neoplasm to bone marrow, bone marrow infection due to the HIV itself, administration of myelodepressive chemotherapies like ZDV, and autoantibody proteins produced due to chemotherapies [14, 15]. However, a number of studies revealed that use of HAART reduces anemia among people living with HIV/AIDS [16, 17]. 
TABLE 1: Cut-off point for blood cells considered in the study.

\begin{tabular}{lcc}
\hline Type of blood cell & Cut-off point & Remark \\
\hline WBC & $\geq 4.5 \times 10^{3}$ cells $/ \mu \mathrm{L}$ & Below normal \\
& $<4.5 \times 10^{3}$ cells $/ \mu \mathrm{L}$ & Below normal \\
Platelet & $\geq 150 \times 10^{3}$ cells $/ \mu \mathrm{L}$ & Commenced for ART \\
& $<150 \times 10^{3}$ cells $/ \mu \mathrm{L}$ & Underweight \\
$\mathrm{CD}_{4}$ & $\geq 200 \mathrm{cells} / \mu \mathrm{L}$ & Normal \\
& $<200 \mathrm{cells} / \mu \mathrm{L}$ & Overweight \\
BMI & $<18.5 \mathrm{~kg} / \mathrm{m}^{2}$ & Obese \\
& $18.5-24.9 \mathrm{~kg} / \mathrm{m}^{2}$ & $25-29.9 \mathrm{~kg} / \mathrm{m}^{2}$ \\
\end{tabular}

Note. $\mathrm{CD} 4=$ cluster of differentiation $4, \mathrm{WBC}=$ white blood cells, $\mathrm{BMI}=$ body mass index, $\mu \mathrm{L}=$ microliter.

Previous studies conducted in Ethiopia showed that the prevalence of anemia among people living with HIV/AIDS taking ART ranged from $20.9 \%$ to $70.1 \%$ [14, 18-20]. Factors that are often associated with anemia among people living with HIV/AIDS include ART regimen, presence of opportunistic infections (OIs), residence, gender, marital status, monthly income, educational status, duration of ART taken, history of antituberculosis (TB) drug treatment, advanced stage of the HIV disease, white blood cell (WBC) count < 4,000 cells $/ \mu \mathrm{L}, \mathrm{CD} 4+\mathrm{T}$-lymphocyte count $<200$ cells $/ \mu \mathrm{L}$, and platelets count $<200,000$ cells $/ \mu \mathrm{L}$ [21-23]. However, there is limited insight regarding the prevalence and factors associated with anemia level among people living with HIV/AIDS taking ART drug in Addis Ababa, Ethiopia. The purpose of this study was to estimate the prevalence and examine factors associated with anemia among people living with HIV/AIDS taking ART drug at ART clinic of Tikur Anbessa Specialized Hospital in Addis Ababa, Ethiopia.

\section{Methods}

2.1. Study Design and Settings. A cross-sectional study design was conducted from April 15 to May 15, 2018, at Tikur Anbessa Specialized Hospital in Addis Ababa, Ethiopia. The hospital is among referral and teaching hospitals of the country located in Addis Ababa. The hospital has HIV/AIDS care-providing center with an average daily client flow of 50-60.

2.2. Sample Size Determination, Sampling Procedure, and Study Subjects. Sample size was estimated using a single population proportion formula and calculated with the following assumptions: $95 \%$ confidence level, 5\% margin of error, and $23 \%$ expected prevalence of anemia among people living with HIV/AIDS [20]. Given these assumptions and considering a nonresponse rate of $10 \%$, the required sample size was found to be 301. Simple random sampling method was used to select charts to be reviewed among charts of clients who have been followed up during the data collection period on daily basis. Charts of client, with incomplete information, age under 18, pregnant women, postpartum period, and ART inexperienced (those who took ART drug for less than three months), were excluded from the study. The most recent data was taken as information recorded for the study from laboratory investigation sheets and other information sheets.

\subsection{Study Variables}

2.3.1. Anemia Level. The anemia level was determined based on WHO report 2001 and a study conducted on pathogenesis and clinical implications of HIV-related anemia in 2013; the anemia level for nonpregnant women was defined as hemoglobin $<12.0 \mathrm{~g} / \mathrm{dl}$ : [severe $<7.0 \mathrm{~g} / \mathrm{dl}$, moderate $=7-9.9$ $\mathrm{g} / \mathrm{dl}$, and mild $=10-11.9 \mathrm{~g} / \mathrm{dl}]$, whereas, for men, it was defined as hemoglobin $<13.0$ : [severe $<9.0 \mathrm{~g} / \mathrm{dl}$, moderate $=9-11.9$ $\mathrm{g} / \mathrm{dl}$, and mild $=12.0-12.9 \mathrm{~g} / \mathrm{dl}][24,25]$.

2.3.2. Sociodemographic and Clinical Characteristics of the Patients. The sociodemographic characteristics identified from the patients' chart include age, gender, residence, religion, ethnic group, marital status, educational status, occupation, and monthly income. Moreover, the clinical and biochemical test characteristics of patients gathered from charts include CD4 count (cells $/ \mu \mathrm{L}), \mathrm{WBC}$ count $($ cells $/ \mu \mathrm{L})$, platelet count (cells $/ \mu \mathrm{L})$, nutritional status $(\mathrm{BMI})\left(\mathrm{kg} / \mathrm{m}^{2}\right)$, WHO clinical stage of HIV/AIDS, ART regimen, and anti-TB treatment history. The CD4 T-lymphocyte was determined based on WHO (World Health Organization) recommendation of 2007 to commence ART for HIV positive peoples [26]. The WBC and platelet ranges were determined based on the guide of Bacovsky J, blood count interpretation for health personnel [27]. In order to assess nutritional status, patients' body mass index was calculated as a proportion of weight in $\mathrm{kg}$ divided by height squared. Then, they were indexed based on body mass index level considered by healthcare practitioners [28]. The clinical stage of HIV/AIDS was used based on the WHO clinical staging classification criteria [26]. The ART regimen was determined based on whether the study participants were taking ZDV-containing ART drug or not. Similarly, treatment history of the client was assessed for being treated for TB or not. Table 1 summarizes the cut-off points used for blood cell levels. 


\subsection{Data Collection Instrument, Data Collection Process-} ing, and Quality Control. The questionnaire (checklist) was developed after reviewing literatures and WHO guidelines. The checklist comprised sociodemographic and clinical characteristics: age, gender, residence, religion, ethnic group, marital status, educational status, occupation, monthly income, and clinical characteristics: CD4 T-lymphocyte, hemoglobin, WBC, platelet count level, BMI level, WHO clinical stage of HIV/AIDS, ART regimen, and history to treatment for TB. Before the actual data collection date, the questionnaire was pretested on $5 \%$ of charts of the study population. Then, necessary modification was done based on its analysis. The study questionnaire was prepared in English. A graduate class nurse student collected the data. Principal orientation was given for data collector prior to the data collection date on how to collect the data and make them familiar with the data collection questionnaire. The completeness of each questionnaire was checked on daily basis.

2.5. Data Analysis. Data was entered using EpiData version 3.1 statistical package software. After thorough cleaning, the data was exported to SPSS version 22 statistical package software for further analysis. Descriptive statistics such as mean, standard deviations (SD), frequency, and percentage were used to describe the variables of the study. In order to describe factors associated with anemia among people living with HIV/AIDS, unadjusted and adjusted odds ratios with their 95\% CI were calculated using logistic regression models.

2.6. Ethical Consideration. The ethical clearance letter was obtained from ethical clearance committee of Addis Ababa University College of Health Sciences. After we offered the letter to the head department of ART clinic, the purpose of the study was clearly stated to the healthcare professionals working in the ART clinic of the Hospital.

\section{Results}

A total of 301 charts were reviewed. The median age was $38 \pm 10.38$. The majority $(62.1 \%)$ of the study participants were female. About half (50.5\%) of the study participants were unemployed. More than three-fourths (90\%) of the study participants were from urban residential area. About half (49.8\%) of the study participants were married. Table 2 summarizes the details of the characteristics of study participants.

3.1. The Clinical and Biochemical Tests Characteristics. The medians $( \pm \mathrm{SD})$ of $\mathrm{CD} 4, \mathrm{WBC}$, and platelet counts were $332 \pm 195.67,5490 \pm 4015$, and $287000 \pm 97499.53$, respectively. The majority $(77.1 \%, 68.4 \%$, and $93.4 \%)$ of the study participant's CD4, WBC, and platelet count were $\geq 200, \geq$ 4500 , and $\geq 150,000$ cells $/ \mu \mathrm{L}$, respectively. Regarding the study participant's nutritional status, $61.5 \%, 20.6 \%, 12 \%$, and $6 \%$ of the study participants were found to be of normal weight, overweight, underweight, and obese in their nutritional status, respectively. Further, almost three-fourths of the
Frequency of anemic vs not anemic study participants with selected variables

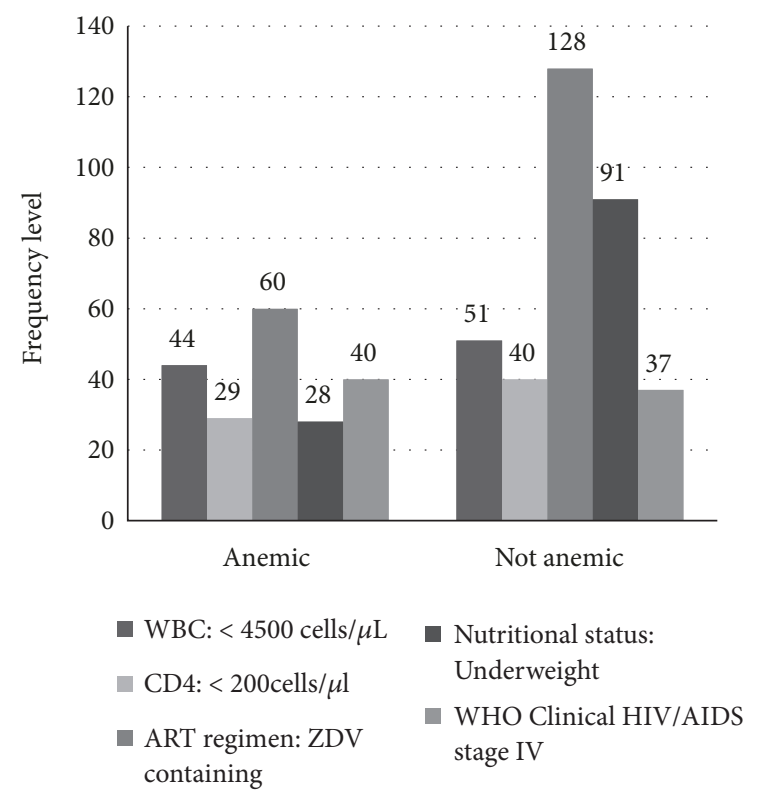

FIGURE 1: Frequency of anemic versus not anemic study participants with selected variables.

study participants were taking ZDV-containing ART drug (ZDV/3TC/NVP) (Table 3).

3.2. Prevalence of Anemia. The prevalence of anemia was $34.6 \%$. Among the overall anemic study participants, 5\%, $15.6 \%$, and $14 \%$ had severe, moderate, and mild level of anemia, respectively. A significant number (48) of study participants were from the age group of 30-39. A momentous number (75 and 60) of anemic study participants had CD4 T-lymphocyte and WBC count $\geq 200$ and $\geq 4500$ cells $/ \mu \mathrm{L}$, respectively. A noteworthy number (40) of anemic study participants were found in stage IV of WHO clinical stage of HIV/AIDS. Regarding ART regimen and anti-TB drug exposure history, a considerable number (60 and 36) of anemic study participants were taking ZDV-containing ART drug (ZDV/3TC/NVP) and had history of anti-TB drug treatment exposure, respectively (Table 3). Among a total of 95 study participants whose WBC count level was $<4500$ cells $/ \mu \mathrm{L}, 44$ were anemic, while the remaining 51 were not anemic. Moreover, among a total of 77 study participants who were found in stage IV of WHO clinical staging of HIV/AIDS, 40 were anemic, while the remaining 37 were not. Further, among a total of 188 study participants who were taking ZDV-containing ART drug (ZDV/3TC/NVP), a considerable number (60) were anemic, while the remaining 128 were not (Figure 1).

3.3. Factors Associated with Anemia. The unadjusted logistic regression analysis revealed that sociodemographic characteristics, gender $\left(\chi^{2}=6.89, p<0.010\right)$ and occupation $\left(\chi^{2}\right.$ 
TABLE 2: Sociodemographic characteristics and their association with anemia under unadjusted logistic regression analysis $(\mathrm{n}=301)$.

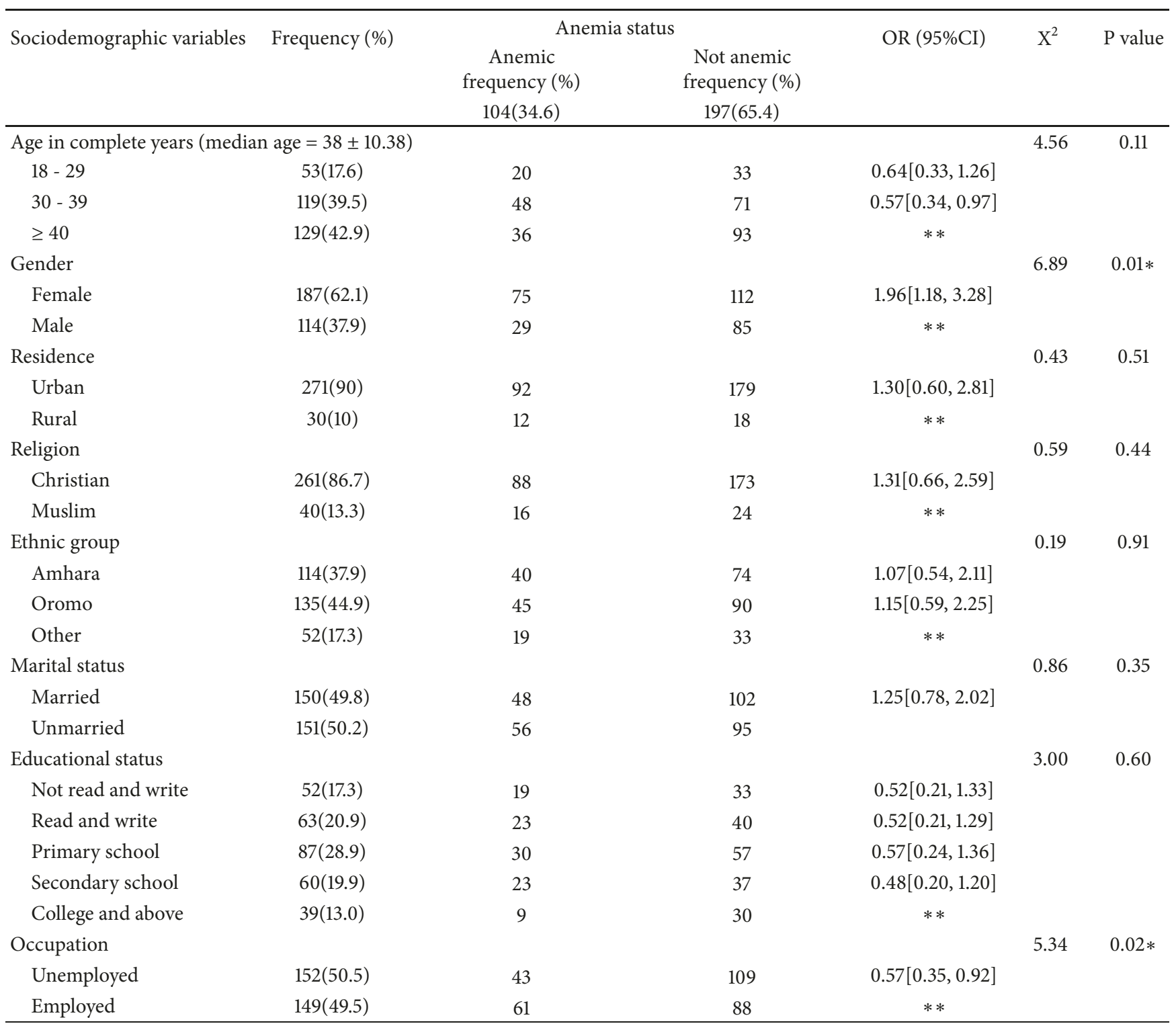

Note. Religion: Christian includes orthodox, protestant, and catholic. Ethnic group: other includes Gurage and Tigre. Marital status: Unmarried includes living together, widowed, single, and divorced. Occupation:unemployed includes merchant, housewife, student, farmer, and daily laborer. Employed includes private and governmental employees.

Statistical significance at $95 \% \mathrm{CI}, \mathrm{P}<0.05 ; * *$ reference; $*$ statistically significant.

$=5.34, p<0.022)$, were significantly associated with anemia (Table 2). Regarding clinical characteristics, WBC count $\left(\chi^{2}\right.$ $=8.33, p<004)$, platelet count $\left(\chi^{2}=5.78, p<0.18\right)$, nutritional status $\left(\chi^{2}=23.45, p<0.001\right)$, and WHO clinical HIV/AIDS stage $\left(\chi^{2}=16.72, p<0.001\right.$, ) were significantly associated with anemia (Table 3 ). The adjusted logistic regression analysis showed that gender $(\mathrm{OR}=2.26[95 \% \mathrm{CI}=1.22,4.16], P<$ 0.009), WBC count ( $\mathrm{OR}=2.30$ [95\% CI $=1.29,4.09], p<$ $0.005)$, platelet count $(\mathrm{OR}=2.89[95 \% \mathrm{CI}=0.99,8.41], p<$ $0.051)$, nutritional status $(\mathrm{OR}=2.05[95 \% \mathrm{CI}=0.69,6.02]$, $p<0.001$ ), and WHO clinical HIV stage (OR $=3.69[95 \%$ $\mathrm{CI}=1.86,7.31], p<0.003)$ were among the different factors associated with anemia among people living with HIV/AIDS (Table 4).

\section{Discussion}

This study assessed the prevalence and factors associated with anemia among people living with HIV/AIDS taking ART for at least three months in Tikur Anbessa Specialized Hospital in Addis Ababa, Ethiopia. It is clear that anemia is a common medical problem affecting people living with HIV/AIDS by complicating the pathogenesis of the disease $[9,19,25]$. Using anemia demarcation level $<13 \mathrm{~g} / \mathrm{dl}[24,25]$, our study found 
TABLE 3: Clinical characteristics and their association with anemia under unadjusted logistic regression analysis $(\mathrm{n}=301)$.

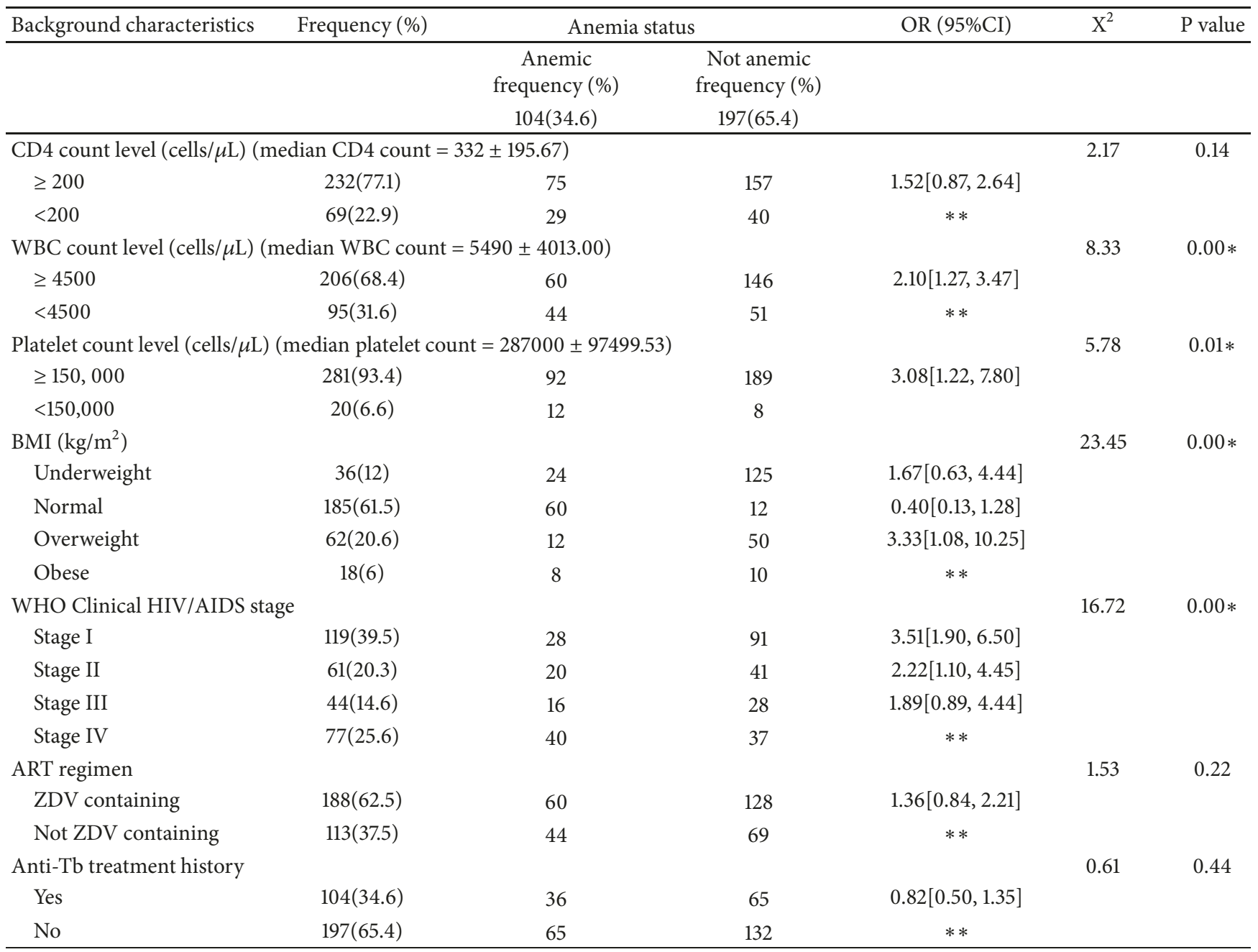

Note: $\mathrm{CD} 4=$ cluster of differentiation $4, \mathrm{WBC}=$ white blood cells, $\mathrm{BMI}=$ body mass index, $\mathrm{ZDV}=$ zidovudine, $\mu \mathrm{L}=$ microliter.

$* *$ reference; $*$ statistically significant.

TABLE 4: Logistic regression analysis showing the association between patient characteristics and anemia among people living with HIV/AIDS $(\mathrm{n}=301)$.

\begin{tabular}{lccccc}
\hline Variables & $\beta$ & SE & Wald $\chi^{2}$ & OR (95\%CI) & P value \\
\hline Gender & 0.81 & 0.31 & 6.80 & $2.26[1.22,4.16]$ & 0.01 \\
WBC count & 0.83 & 0.29 & 7.99 & $2.30[1.29,4.09]$ & 0.01 \\
Platelet count & 1.06 & 0.55 & 3.80 & $2.89[0.99,8.41]$ & 0.05 \\
Nutritional stats & 0.72 & 0.55 & 17.92 & $2.05[0.69,6.02]$ & 0.00 \\
WHO HIV/AIDS clinical staging & 1.31 & 0.35 & 14.31 & $3.69[1.86,7.31]$ & 0.00 \\
\hline
\end{tabular}

Note. HIV/AIDS = Human Immune Deficiency Virus/Acquired Immune Deficiency Syndrome, SE = standard error, WBC $=$ white blood cells, OR $=$ odds ratio, $\mathrm{CI}=$ confidence interval.

that the prevalence of anemia was $34.6 \%$. This figure is lower when compared to previous studies completed in Ethiopia (the prevalence ranged from $43 \%$ to $70.1 \%$ ) $[9,14,22]$, Iran, Nigeria, China, and Nepal, ranging between 51.5 and $71 \%$ $[13,29-33]$. However, the prevalence of anemia reported in this study was higher than a number of studies conducted in different parts of Ethiopia ranging between 20.8 and 23.1\% $[18,20,21,34-37]$ and South Africa (25.8\%) [10]. Moreover, this study revealed that $5 \%, 15.6 \%$, and $14 \%$ of the study participants had severe, moderate, and mild level of anemia, respectively. This finding is in line for the severe level of anemia while it is lower for moderate and mild level of anemia in another study from Ethiopia [36]. The possible reason for the difference observed in prevalence of anemia may be due to the difference in socioeconomic level, difference in study participants' WHO clinical HIV/AIDS staging level, 
difference in ART regimen taking, presence/absence and/or level of opportunistic infections, lack of awareness about appropriate nutrition, and inclusion and/or exclusion criteria in recruiting study participants.

The finding of this study indicates that almost one-third of the study participants were anemic, which is a concern, as untreated anemia in people living with HIV/AIDS and/or taking ART is associated with pathophysiologic changes and progression of the disease to advanced stage and finally may result in death of the individual [25]. Thus, there should be an intervention that has an ultimate effect in reducing mortality related to complications of anemia among people living with HIV/AIDS and/or taking ART drug.

Factors associated with anemia include gender, occupation, WBC count, platelet count, nutritional status, and WHO clinical staging level. These findings are partly in line with similar previous study findings $[9,11,18,21]$. According to the findings of this study, females were more likely to be anemic compared to males. This finding is in line with studies from Nigeria and South Africa [10, 29]. However, the unemployed study participants were less likely to be anemic compared to the employed study participants. Similarly, younger study participants were found to be less likely to be anemic compared to the elders. This finding is in line with studies from Ethiopia $[10,14]$. This may be due to the fact that the younger study participants' cell proliferating organs have more competent proliferation capacity of red blood cell and the participants themselves are more aware about benefit of consuming more nutritional diet and/or have a better socioeconomic and educational status.

Moreover, we found that underweight study participants were more likely to be anemic, while those with normal weight were less likely to be anemic. This finding is consistent with previous studies conducted in developing countries [10, $12,38]$. This may be due to the fact that the underweight individuals are less aware about the benefit of appropriate nutrition consumption and/or have a less socioeconomic and educational condition or may have less adherence to ART drug therapy. Further, those study participants taking ZDVcontaining ART drug were found more likely to be anemic compared to those who were not. This finding is in line with similar studies from Ethiopia [11, 13, 20,35]. This is usually due to the side effect of the ART drug ZDV resulting in manifestation of granulocytopenia, anemia, malaise, fatigue, and other gastrointestinal symptoms [39].

Bearing in mind the effect of anemia and its significant prevalence, it is a great disquiet that more than one-third of the study participants were anemic, while appropriate treatment options are available and the study participants were on ART drug for at least three months, which have an effect to combat the pathogenesis of the disease. Therefore, based on the findings of this study, the following interventions are suggested to detect and combat anemia among people living with HIV/AIDS taking ART drug. (1) Monitor hemoglobin level on each of the follow-up periods by focusing on those people taking ART drug regimen containing ZDV and take appropriate action to combat the anemia if anemia is detected. This is because the pathogenesis of anemia is worrisome and ZDV by itself has an effect on reducing proliferation of red blood cells. (2) Monitor adherence level of the people living with HIV/AIDS taking ART drug to their therapy and motivate, encourage, and advise them to adhere to the ART drug therapy consistently to gain its therapeutic effect. This is because ART drug has an effect on combating anemia among people living with HIV/AIDS taking ART drug. (3) Monitor and take quick appropriate action for drugdrug interaction and magnified side effects of each drug which may occur in people living with HIV/AIDS taking ART drug. This is because drug-drug interaction and side effects of some drugs by themselves interfere with reduced proliferation of granulocytes and contribute to raising immature destruction of cells. (4) Increase awareness of people living with HIV/AIDS taking ART drug about the benefit of adhering to consumption of nutritional diet consistently. This is because consuming appropriate diet helps the body in proliferating enough amounts of red blood cells and other granulocytes. This study has limitations. Firstly, it is a crosssectional study that has chicken egg dilemma in identifying causal relationship. Secondly, the study excludes people living with HIV/AIDS who are naïve to ART drug. Thus, it is recommended that future study considers longitudinal study by considering ART-naïve people living with HIV/AIDS by determining the severity of anemia.

In conclusion, it is important to alleviate anemia among people living with HIV/AID taking ART drug, as the presence of anemia among people living with HIV/AIDS fastens the progression of the disease to the advanced stages. The suggested intervention by this study focused at improving nutritional status of people living with HIV/AIDS taking ART drug through enhancing awareness of benefit of consuming balanced diet and monitoring and managing granulocytes level appropriately, which increases survival rate; it is best to monitor granulocytes like $\mathrm{CD} 4$ count, platelet and WBC count, and hemoglobin level more frequently. It is also good to focus on sociodemographic characteristics like gender and occupation of the client, which have an ultimate effect in affecting level of anemia among people living with HIV/AIDS.

\section{Data Availability}

The data used to support the findings of this study are available from the corresponding author upon request.

\section{Conflicts of Interest}

The authors declare that they do not have any conflicts of interest.

\section{Acknowledgments}

The authors are grateful to data collectors for collecting the data per the instruction given and healthcare workers in the ART clinic of the hospital for their cooperation in the data collection process. 


\section{References}

[1] N. J. Kassebaum, T. D. Fleming, A. Flaxman et al., "The global burden of anemia," Hematology/Oncology Clinics of North America, vol. 30, no. 2, pp. 247-308, 2016.

[2] WHO, "Global estimates of the prevalence of anaemia in infants and children aged 6-59 months," http://www.who.int/nutrition/ publications/micronutrients/globalprevalenceanaemia, 2011.

[3] "United States Department of Health and Human Service National institute of Health, National Heart, Lung and blood institute. Guide to anemia," 2011, https://www.nhlbi.nih.gov/ files/docs/public/blood/anemia-inbrief_yg.pdf.

[4] WHO, "Towards an integrated approach for effective anaemia control," 2004, http://www.who.int/nutrition/publications/micronutrients/WHOandUNICEF_statement_anaeiaen.pdf.

[5] O. Ifudu, "Maximizing response to erythropoietin in treating HIV-associated anemia," Cleveland Clinic Journal of Medicine, vol. 68, no. 7, pp. 643-648, 2001.

[6] "Johns Hopkins University and Parul Christian International Nutrition, Iron Deficiency and Anemia Causes, Consequences, and Solutions," http://ocw.jhsph.edu/courses/InternationalNutrition/PDFs/Lecture5.pdf, 2005.

[7] P. A. Volberding, A. M. Levine, D. Dieterich, D. Mildvan, R. Mitsuyasu, and M. Saag, "Anemia in HIV infection: clinical impact and evidence-based management strategies," Clinical Infectious Diseases, vol. 38, no. 10, pp. 1454-1463, 2004.

[8] B. Dikshit, A. Wanchu, R. K. Sachdeva, A. Sharma, and R. Das, "Profile of hematological abnormalities of Indian HIV infected individuals," BMC Blood Disorders, vol. 9, article 5, 2009.

[9] A. G. Alamdo, T. Fiseha, A. Tesfay, M. K. Deber, Z. M. Tirfe, and T. Tilahun, "Anemia and its associated risk factors at the time of antiretroviral therapy initiation in public health facilities of Arba Minch Town, Southern Ethiopia," Health, vol. 07, no. 12, pp. 1657-1664, 2015.

[10] S. Takuva, M. Maskew, A. T. Brennan, I. Sanne, A. P. Macphail, and M. P. Fox, "Anemia among HIV-infected patients initiating antiretroviral therapy in South Africa: improvement in hemoglobin regardless of degree of immunosuppression and the initiating art regimen," Journal of Tropical Medicine, vol. 2013, Article ID 162950, 6 pages, 2013.

[11] F. Masaisa, J. B. Gahutu, J. Mukiibi, J. Delanghe, and J. Philippé, "Anemia in human immunodeficiency virus-infected and uninfected women in Rwanda," The American Journal of Tropical Medicine and Hygiene, vol. 84, no. 3, pp. 456-460, 2011.

[12] R. Subbaraman, B. Devaleenal, P. Selvamuthu et al., "Factors associated with anaemia in HIV-infected individuals in southern India," International Journal of STD \& AIDS, vol. 20, no. 7, pp. 489-492, 2009.

[13] M. Meidani, F. M. Rezaei, R. A. Mohammad, and T. K. Majid, "Prevalence, severity, and related factors of anemia in HIV/AIDS patients," Journal of Research in Medical Sciences, vol. 17, no. 2, pp. 138-142, 2012.

[14] M. Alem, T. Kena, N. Baye, R. Ahmed, and S. Tilahun, "Prevalence of anemia and associated risk factors among adult HIV patients at the anti-retroviral therapy clinic at the university of gondar hospital, Gondar, Northwest Ethiopia," Open Access Scientific Reports, vol. 2, no. 3, 2013.

[15] "Government of Nepal Ministry of Health \& Population National Centre for AIDS \& STD Control, National Antiretroviral Therapy Guidelines," 2009, http://www.who.int/hiv/ pub/guidelines/nepal_art.pdf?ua $=1$.
[16] K. Berhane, R. Karim, M. H. Cohen et al., "Impact of highly active antiretroviral therapy on anemia and relationship between anemia and survival in a large cohort of HIV-infected women: women's interagency HIV study," Journal of Acquired Immune Deficiency Syndromes, vol. 37, no. 2, pp. 1245-1252, 2004.

[17] P. S. Belperio and D. C. Rhew, "Prevalence and outcomes of anemia in individuals with human immunodeficiency virus: a systematic review of the literature," American Journal of Medicine, vol. 116, no. 7, pp. 27-43, 2004.

[18] M. Assefa, W. E. Abegaz, A. Shewamare, G. Medhin, and M. Belay, "Prevalence and correlates of anemia among HIV infected patients on highly active anti-retroviral therapy at Zewditu Memorial Hospital, Ethiopia," BMC Hematology, vol. 15, no. 1, p. 6, 2015.

[19] B. Enawgaw, M. Alem, M. Melku, Z. Addis, B. Terefe, and G. Yitayew, "Prevalence and associated risk factors of anemia among HIV infected children attending Gondar university hospital, Northwest Ethiopia: a cross sectional study," BMC Hematology, vol. 15, no. 1, p. 12, 2015.

[20] H. Melese, M. M. Wassie, H. Woldie, A. Tadesse, and N. Mesfin, "Anemia among adult HIV patients in Ethiopia: A hospitalbased cross-sectional study," HIV/AIDS - Research and Palliative Care, vol. 9, pp. 25-30, 2017.

[21] L. Gedefaw, T. Yemane, Z. Sahlemariam, and D. Yilma, "Anemia and risk factors in HAART naïve and HAART experienced HIV positive persons in South West Ethiopia: a comparative study," PLoS ONE, vol. 8, no. 8, Article ID e72202, 2013.

[22] K. Tadesse, F. Haile, and N. Hiruy, "Predictors of mortality among patients enrolled on antiretroviral therapy in Aksum hospital, Northern Ethiopia: a retrospective cohort study," PLoS ONE, vol. 9, no. 1, Article ID e87392, 2014.

[23] H. M. Wolde, W. T. Lerebo, K. H. Girmay, and Y. A. Melaku, "Incidence and risk factors of anemia among HIV/AIDS patients taking anti-retroviral terapy at tertiary hospitals in Addis Ababa, Ethiopia: a retrospective cohort study," Journal of HIV/AIDS \& Infectious Diseases, vol. 2, no. 303, 2014.

[24] WHO, "WHO Hemoglobin Cut - Offs," 2001, https://www .k4health.org/toolkits/anemia-prevention/hemoglobin-cut-offs.

[25] A. J. Redig and N. Berliner, "Pathogenesis and clinical implications of HIV-related anemia. HIV in heamatology," http:// asheducationbook.hematologylibrary.org/content/2013/1/377 .full.pdf, 2013.

[26] World Health Organization, "Labratory Guidelines for enumerating CD4 T Lymphoctes in the context of HIV/AIDS," 2007, http://www.who.int/hiv/amds/LaboratoryGuideEnumeratingCD4TLymphocytes.pdf.

[27] J. Bacovsky, "Blood count interpretation," http://public.fnol .cz/www/3ik/data/soubory_en/bacovsky_blood_count.pdf.

[28] "Center for Disease Control and Prevention, Body Mass Index considerations for Practitioners," https://www.cdc.gov/obesity/ downloads/bmiforpactitioners.pdf.

[29] G. R. Pennap and K. Abubakar, "Prevalence of anemia among human immunodeficiency virus infected patients accessing healthcare in Federal Medical Center Keffi, Nigeria," International Journal of Tropical Disease \& Health, vol. 10, no. 3, pp. 1-7, 2015.

[30] Y. Shen, Z. Wang, H. Lu et al., "Prevalence of anemia among adults with newly diagnosed HIV/AIDS in China," PLoS ONE, vol. 8, no. 9, p. e73807, 2013.

[31] C. Martin, K. Poudel-Tandukar, and K. C. Poudel, "HIV symptom burden and anemia among HIV-positive individuals: 
cross-sectional results of a community-based positive living with HIV (POLH) study in Nepal," PLoS ONE, vol. 9, no. 12, Article ID ell6263, 2014.

[32] R. Omoregie, E. U. Omokaro, O. Palmer et al., "Prevalence of anaemia among HIV-infected patients in Benin City, Nigeria," Tanzania Journal of Health Research, vol. 11, no. 1, pp. 1-4, 2009.

[33] R. E. Ahumareze, J. Rankin, A. David et al., "Prevalence of anaemia and the relationship between haemoglobin concentration and CD4 count in HIV positive children on highly active antiretroviral therapy (HAART) in Lagos, Nigeria," Current Pediatric Research, vol. 20, no. 1-2, pp. 29-36, 2016.

[34] Z. Tamir, J. Alemu, and A. Tsegaye, "Anemia among HIV infected individuals taking ART with and without zidovudine at Addis Ababa, Ethiopia," Ethiopian Journal of Health Sciences, vol. 28, no. 1, pp. 73-82, 2018.

[35] M. Wubetu and E. Mebratu, "Assessment of the prevalence of zidovudine induced anemia among adult HIV/AIDS patients on HAART in an ethiopian hospital," Occupational Medicine \& Health Affairs, vol. 6, no. 1, 2018.

[36] H. Mihiretie, B. Taye, and A. Tsegaye, "Magnitude of anemia and associated factors among pediatric HIV/aids patients attending Zewditu memorial hospital art clinic, Addis Ababa, Ethiopia," Anemia, vol. 2015, Article ID 479329, 2015.

[37] T. Deressa, D. Damtie, and M. Melku, "Anemia and thrombocytopenia in the cohort of HIV-infected adults in northwest Ethiopia: a facility-based cross-sectional study," The Journal of International Federation of Clinical Chemistry and Labratory Medicine, vol. 29, no. 1, 2018.

[38] P. Mijiti, Z. Yuexin, L. Min, M. Wubuli, P. Kejun, and H. Upur, "Prevalence and predictors of anaemia in patients with HIV infection at the initiation of combined antiretroviral therapy in Xinjiang, China," International Journal of STD \& AIDS, vol. 26, no. 3, pp. 156-164, 2015.

[39] R. Sperling, "Effect of ART drug ZDV(Zidovudine)," Infectious Diseases in Obstetrics and Gynecology, vol. 6, pp. 197-203, 1998. 


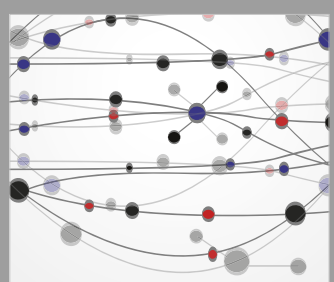

The Scientific World Journal
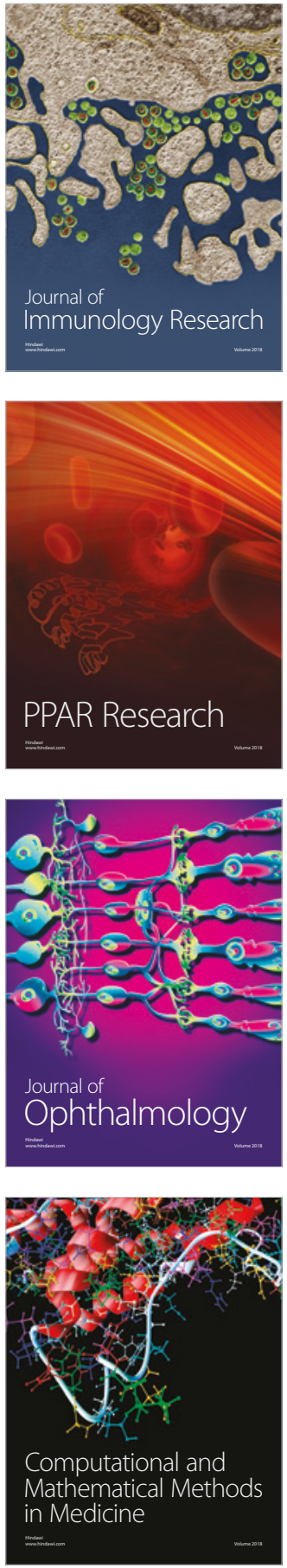

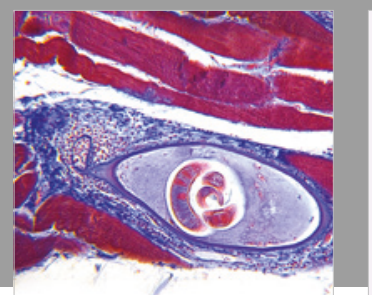

Gastroenterology Research and Practice

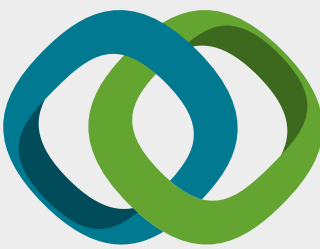

\section{Hindawi}

Submit your manuscripts at

www.hindawi.com
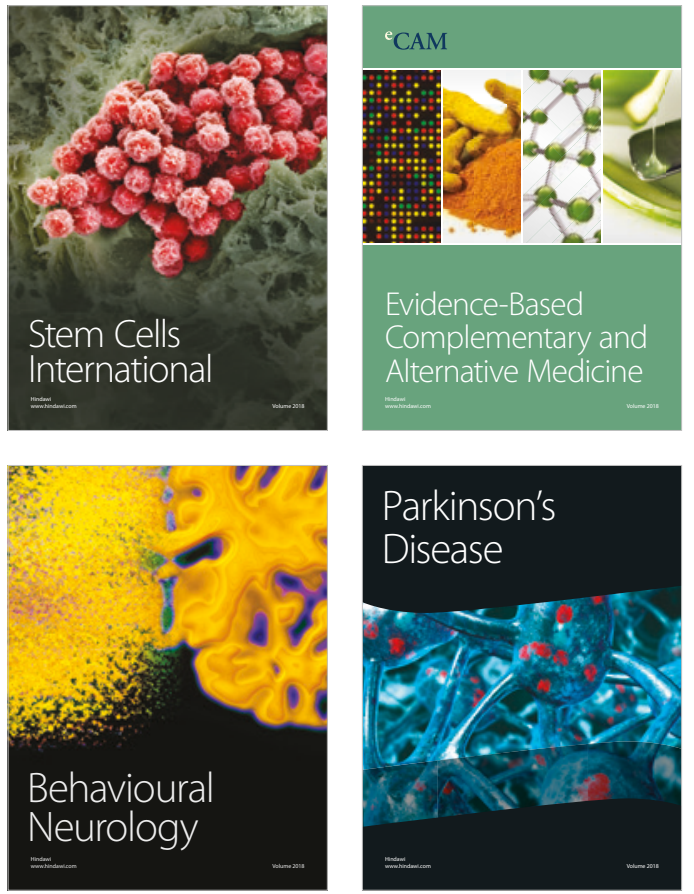

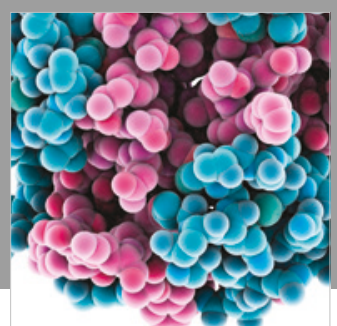

ournal of

Diabetes Research

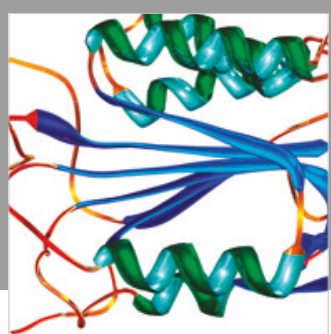

Disease Markers
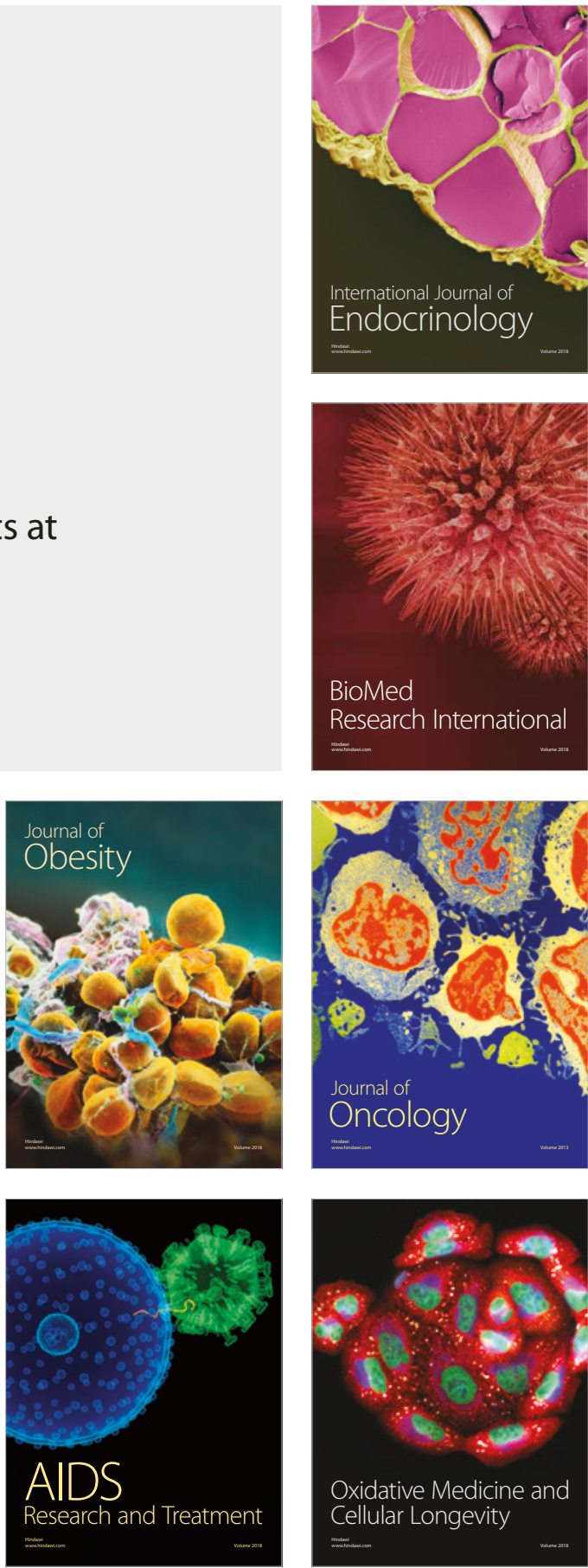